Fever, jaundice, and hepatomegaly

\section{Unusual cause of fever, jaundice, and hepatomegaly in a middle aged man}

\section{S Kumar, S Uthamalingam, A R Vasudevan, A Lim, A Feliz, J M Brensilver, R Yarrish}

Answers on $p 569$.

A 48 year old man presented with gradual onset of fever, anorexia, episodic nausea and vomiting, a 40 pound weight loss, and deepening jaundice over a six week period. Fever was intermittent and associated with chills and rigors. There was no history of pain in the right hypochondrium, pruritus, or clay coloured stools. The patient had a 30 pack year smoking history and consumed alcohol in moderation. He took no medications. Five years previously, he had an emergent laparotomy after a motor vehicle accident, details of which he was unable to supply. He was a native of El Salvador, but had been residing in

the northeastern United States for the past four years. He was a gardener by occupation. There was no history of travel abroad during this time.

On examination, the temperature was $39^{\circ} \mathrm{C}$, pulse rate 92 beats $/ \mathrm{min}$, blood pressure $120 / 60 \mathrm{~mm} \mathrm{Hg}$, and respiratory rate 18 breaths $/ \mathrm{min}$. There was no significant lymphadenopathy. He was markedly icteric, but there was no rash or stigmata of chronic liver disease. Cardiorespiratory examination was within normal limits. Abdominal examination revealed a midline scar. The liver was palpable $8 \mathrm{~cm}$ beneath the right costal margin and percussed to a liver span of

Table 1 Laboratory values on presentation

\begin{tabular}{|c|c|c|}
\hline Test & Value & Normal range \\
\hline Haemoglobin (g/l) & 86 & $140-180$ \\
\hline Packed cell volume & 0.26 & $0.42-0.52$ \\
\hline Leucocyte count $\left(\times 10^{9} / \mathrm{I}\right)$ & 12 & $4-11$ \\
\hline Platelet count $\left(\times 10^{\circ} / \mathrm{l}\right)$ & 169 & $130-400$ \\
\hline Mean corpuscular volume (fl) & 100 & $86-98$ \\
\hline Red cell distribution width & 0.24 & $0.13-0.15$ \\
\hline Reticulocyte count (\%) & 12 & $0.2-2$ \\
\hline Lactate dehydrogenase (U/I) & 1200 & $100-190$ \\
\hline Sodium (mmol/l) & 136 & $136-145$ \\
\hline Potassium (mmol/l) & 4.4 & $3.5-5.0$ \\
\hline Blood urea nitrogen $(\mathrm{mmol} / \mathrm{l})$ & 8.2 & $3.6-7.1$ \\
\hline Creatinine ( $\mu \mathrm{mol} / \mathrm{l})$ & 150.2 & $50-130$ \\
\hline Glucose (mmol/I) & 7.54 & $3.5-7.8$ \\
\hline Amylase (U/I) & 55 & $60-180$ \\
\hline Total bilirubin ( $\mathrm{mmol} / \mathrm{I})$ & 265 & $5.1-17$ \\
\hline Direct bilirubin ( $\mu \mathrm{mol} / \mathrm{l})$ & 140 & $1.7-5.1$ \\
\hline Aspartate aminotransferase (U/l) & 96 & $15-45$ \\
\hline Alanine aminotransferase (U/I) & 49 & $15-45$ \\
\hline Alkaline phosphatase (U/I) & 217 & $30-120$ \\
\hline Total protein (g/l) & 56 & $55-80$ \\
\hline Albumin (g/l) & 23 & $35-55$ \\
\hline International normalised ratio & 1.1 & $0.7-1.1$ \\
\hline Activated partial thromboplastin time (sec) & 29.3 & Up to 32.3 \\
\hline
\end{tabular}

Table 2 Laboratory findings over days 2-4

\begin{tabular}{llllll}
\hline & $\begin{array}{l}\text { Haemoglobin } \\
(\mathbf{g} / \mathrm{l})\end{array}$ & MCV (fl) & $\begin{array}{l}\text { Reticulocyte } \\
\text { count (\%) }\end{array}$ & $\begin{array}{l}\text { Total/direct } \\
\text { bilirubin ( } \mu \mathrm{mol} / \mathrm{I})\end{array}$ & LDH (U/I) \\
\hline Day 2 & 70 & 104 & 12 & $280 / 170$ & - \\
Day 3 & 68 & 108 & - & - & 1320 \\
Day 4 & 63 & 115 & 21 & $275 / 158$ & - \\
\hline
\end{tabular}

MCV, mean corpuscular volume; LDH, lactate dehydrogenase.

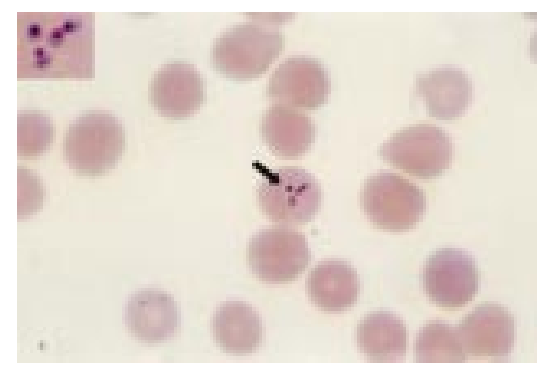

Figure 1 Peripheral blood smear (Wright-Giemsa stain).

$16 \mathrm{~cm}$. It was tender, firm, and smooth surfaced. The spleen was not palpable, and there was no shifting dullness. Neurological examination was normal.

Laboratory values on admission are shown in table 1. Viral hepatitis profile was negative for hepatitis A, B, and C viruses. Monospot test (infectious mononucleosis) and ELISA test for HIV were negative. Urinalysis revealed large bilirubin and urobilinogen $>8 \mathrm{EU} / \mathrm{dl}$ (normal $<1 \mathrm{EU} / \mathrm{dl})$. Chest radiography was normal. A computed tomogram of the abdomen showed diffuse hepatomegaly without biliary dilatation or gallstones; the spleen was not visualised. Electrocardiogram showed sinus tachycardia.

Over the next 48 hours, the patient complained of increasing lassitude and dyspnoea. He had intermittent fever with chills, but physical examination was otherwise unchanged. Laboratory findings over days 2-4 are summarised in table 2. Serum haptoglobin on day 3 was less than $0.06 \mathrm{~g} / \mathrm{l}$ (normal 0.5-2.2 $\mathrm{g} / \mathrm{l})$. Multiple blood cultures and a urine culture were done, all of which showed no growth as of day 4. A peripheral blood smear was taken (see fig l).

\section{QUESTIONS}

(1) In this patient's clinical context, how do you interpret the laboratory tests on admission (table 1) and those done between days $2-4$ (table 2 )?

(2) What does the blood smear show (fig 1)? What is the differential diagnosis?

(3) How would you treat this patient? What are the common complications of this condition?

Postgrad Med J 2002;78:566

\section{Authors' affiliations}

S Kumar, S Uthamalingam, A R Vasudevan, A Lim, J M Brensilver, Sound Shore Medical Center of Westchester (SSMCW), New York Medical College, 16 Guion Place, New Rochelle, NY 10802, USA: Department of Medicine

A Feliz, R Yarrish, Department of Pathology

Correspondence to: Dr Yarrish; soundshoremed@nymc.edu

Submitted 25 February 2002

Accepted 25 March 2002 
Failure to thrive

\section{Failure to thrive in a 3 month old boy}

\section{Basu, S Ferns, M Arun Prasad, P Nalini}

\section{QUESTIONS}

(1) What are the radiological findings and findings on peripheral smear and bone marrow?

(2) What is the diagnosis? What are the possible differential diagnoses?

(3) What is the prognosis and treatment of this condition?

Postgrad Med J 2002;78:567

\section{Authors' affiliations}

D Basu, M A Prasad, Jawaharlal Institute of Post Graduate Medical Education and Research, Pondicherry, India: Department of Pathology

S Ferns, P Nalini, Department of Pediatrics

Correspondence to: Dr Debdatta Basu, Department of Pathology, JIPMER, Pondicherry 605006, India; ddbasu@ satyam.net.in

Submitted 24 January 2002

Accepted 25 March 2002

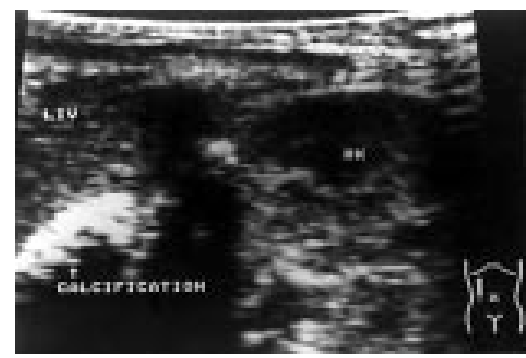

Figure 3 Ultrasound of the abdomen showing calcification in the region of the adrenals. count of $25 \times 10^{9} / 1$, total leucocyte coun of $13 \times 10^{9} / \mathrm{l}$, and many lymphocytes

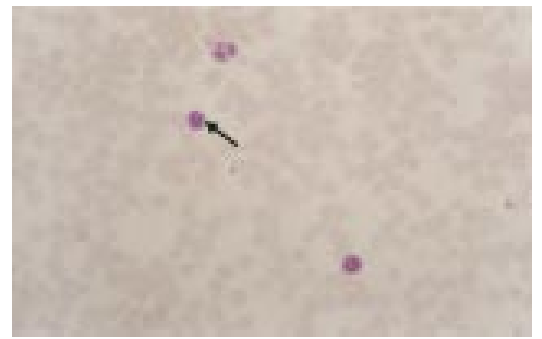

Figure 1 Peripheral smear showing vacuolated lymphocytes (Leishman's stain $x$ 1000).

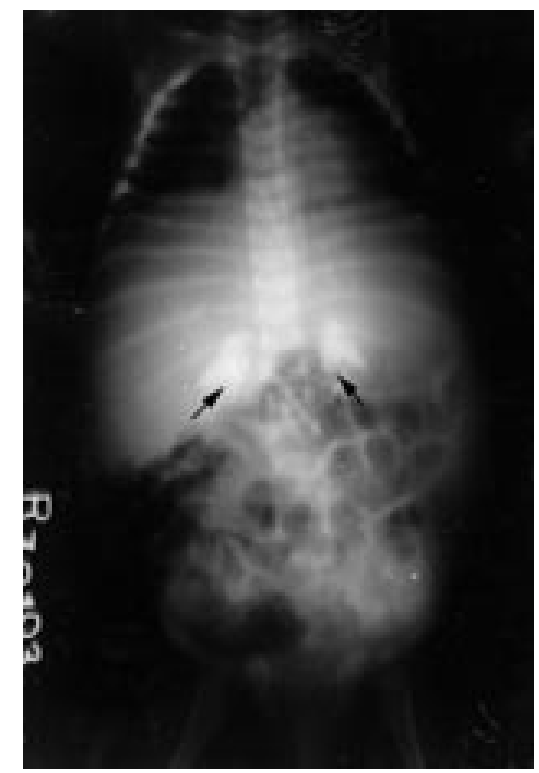

Figure 2 Radiograph of the chest and abdomen showing bilaterally symmetrical and enlarged adrenals with stippled calcification. 


\title{
Refusal to walk in an afebrile well toddler
}

\author{
S Lim, W Sinnathamby, H Noordeen
}

Answers on $p 570$.

$\Lambda$ 19 month old well boy presented with a week's history of refusal to walk unsupported and favouring crawling. He had been increasingly unsteady during the preceding three weeks and appeared to be in pain during nappy changes when both legs were held flexed and abducted at the hips. There was no recent feverish illness or trauma. Bowel and bladder function was normal. His development had been age appropriate to date. He walked unsupported at 1 year of age and had been an active member in a child care group. Examination revealed symmetrically decreased deep tendon reflexes of the lower limbs with flexor plantar response. Lower limb musculature and spine looked normal. Anal tone and hip examination was normal. $\mathrm{He}$ pulled easily to stand and would only

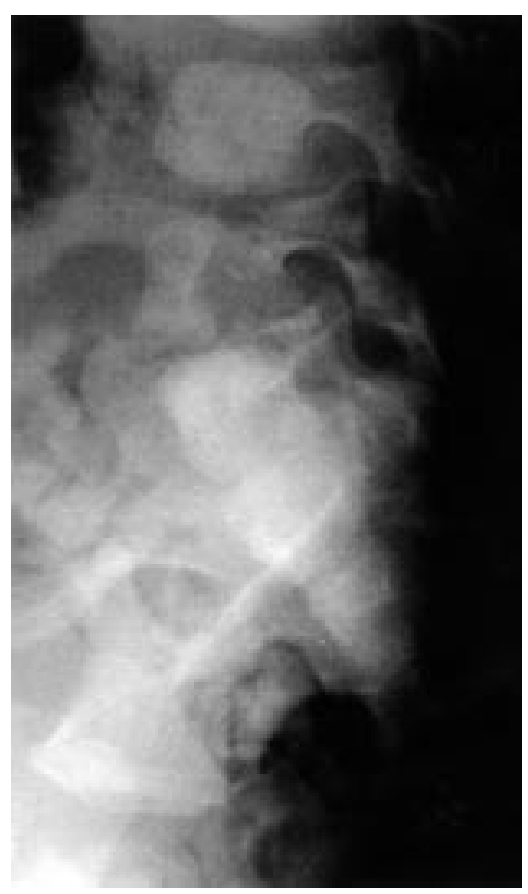

Figure 1 Radiograph of spine on admission (lateral view).

take a few steps across the room when supported. He crawled well with no obvious asymmetry of movements. Investigations revealed raised $\mathrm{C}$ reactive protein of $45 \mathrm{mg} / \mathrm{l}$, erythrocyte sedimentation rate of $73 \mathrm{~mm} /$ hour, and a white cell count of $8.5 \times 10^{9} / 1$ (neutrophil count $\left.2.98 \times 10^{9} / 1\right)$. Ultrasound of the hips and abdomen and a bone scan were normal. Rheumatoid and viral serological screens were negative as were all blood cultures. Plain radiography of the thoracolumbosacral region showed loss of the disc height at the L5-S1 level and loss of clarity of the adjacent end plates (fig 1). He had magnetic resonance imaging of the spine (fig 2). He was given a three week course of antibiotics (parenteral ceftriaxone and oral sodium fusidate for the first 10 days followed by oral flucloxacillin and sodium fusidate for the rest of the course). Before starting antibiotics, C reactive protein had fallen to $2.9 \mathrm{mg} / \mathrm{l}$, lower limb reflexes were more easily

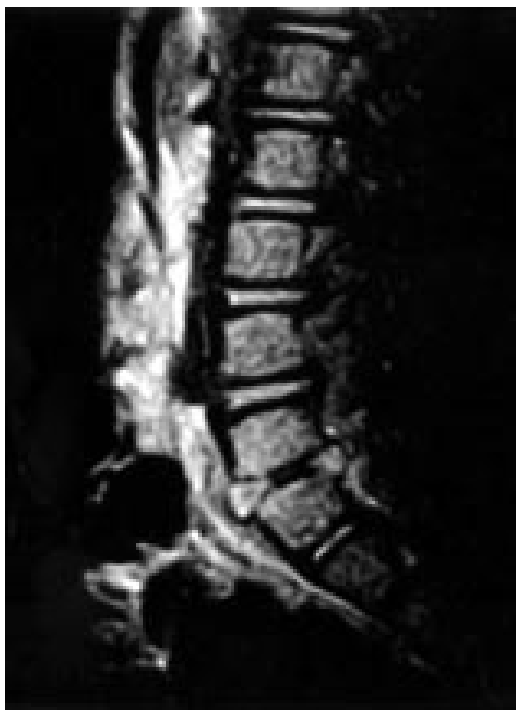

Figure 2 Magnetic resonance image of the spine on admission.

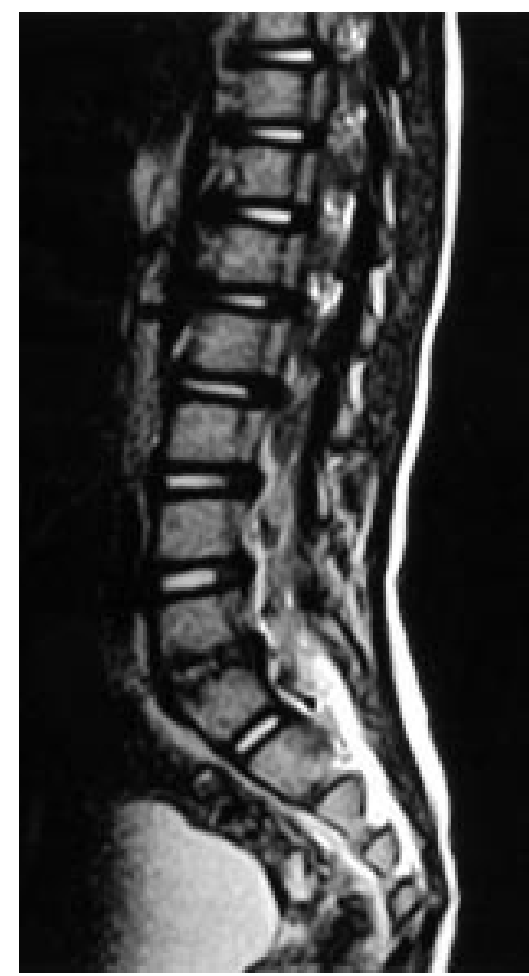

Figure 3 Follow up magnetic resonance image of the spine one year later.

elicited, and he was standing unsupported for longer periods. By the end of the course of antibiotics, the inflammatory markers had normalised and he was able to walk unsupported. More recent $x$ rays did show that there was no significant disruption of the disc space. Repeat magnetic resonance imaging of the spine a year later is shown in fig 3.

\section{QUESTIONS}

(1) What is the likely diagnosis and what do the magnetic resonance imaging studies (figs 2 and 3) show?

(2) What are the alternative differential diagnoses of refusal to walk in a well afebrile toddler?

Postgrad Med J 2002;78:568

\section{Authors' affiliations}

S Lim, W Sinnathamby Paediatric Department, St John's Hospital, Wood Street, Chelmsford CM2 9BG, UK

H Noordeen, Department of Orthopaedics, Great Ormond Street Hospital, London

Correspondence to Dr Lim; sharon.lim@meht.nhs.uk Submitted 25 February 2002

Accepted 25 March 2002 